\title{
ARTERIOVENOUS MALFORMATIONS
}

\section{VEIN OF GALEN AVM AND VISUAL LOSS}

Visual loss as a presenting symptom of an arteriovenous malformation (AVM) of the vein of Galen is reported in a 5-year-old girl from the Royal Liverpool Children's Hospital, Alder Hey, Liverpool, UK. Her vision had been deteriorating for 6 months. On examination, she had no light perception in the left eye, 6/60 acuity in the right eye, and a left hemianopia. Funduscopic exam revealed left optic atrophy and dilated vessels on the right disc. Her left cheek was enlarged with prominent veins. MRI showed a large, deep-seated central AVM involving the vein of Galen. Ultrasound studies showed reversal of flow in the right superior ophthalmic vein and minimal left ophthalmic artery flow. A mild degree of hydrocephalus developed and required shunting after 2 years. (Kaye LC, Kaye SB, Lagnado $\mathrm{R}$ et al. Cerebral arteriovenous malformation presenting as visual deterioration in a child. Dev Med Child Neurol Oct 2000;42:704-706). (Respond: Stephen B Kaye MD FRCOphth, Department of Ophthalmology, Royal Liverpool Children's Hospital, Eaton Road, Alder Hey, Liverpool L12 2AP, UK).

COMMENT. Aneurysm of the vein of Galen (great cerebral vein) is formed by a direct connection between the posterior cerebral artery and the internal cerebral vein that drains into the great cerebral vein. The usual clinical effects of a vein of Galen malformation or ectasia include a high output cardiac failure in the neonatal period, hydrocephalus caused by compression of the cerebral aqueduct, intracranial hemorrhage, and ischemia secondary to a vascular steal phenomenon. Secondary signs include distension of scalp veins and intracranial bruit. The local effects may include visual field defects, proptosis, nystagmus, optic atrophy, papilledema, and retinopathy. The authors' review of the literature found no case of visual loss in a child with vein of Galen AVM and only one adult case presenting with visual symptoms.

Treatment of AVM and vein of Galen ectasia is reviewed in Progress in Pediatric Neurology III (PNB Publ, 1997;p454). Transarterial embolization of feeding arteries using bucrylate is recommended in the absence of complications (Swanstrom S et al. 1994). A free interval between birth and development of cardiac failure is a favorable sign. The use of contrast material for CT is considered inadvisable. In one case report, treatment by embolization with helical stainless steel coils inserted along the straight sinus was successful (McCord FB et al, 1987; reviewed in Progress in Pediatric Neurology I, 1991;p386).

\section{HEADACHE DISORDERS}

\section{SUMATRIPTAN NASAL SPRAY FOR ACUTE MIGRAINE}

A multicenter, randomized, double-blind, placebo-controlled trial of sumatriptan nasal spray ( $5 \mathrm{mg}, 10 \mathrm{mg}$, and $20 \mathrm{mg}$ ) was conducted in 653 adolescents presenting with acute migraine at the Palm Beach Headache Center, Florida; Cleveland Clinic, OH; Michigan Headache Institute, Ann Arbor; and San Antonio Center, TX. All 3 dosages studied were effective in providing headache relief within 1 or 2 hours postdose. Younger patients 12-14 years of age reported higher efficacy rates at lower doses, while older patients 15-17 years of age obtained the greatest benefit at the $20 \mathrm{mg}$ dose of sumatriptan NS. Photophobia and phonophobia were significantly reduced within 2 hours of treatment with the $20 \mathrm{mg}$ dose, and headache recurrence was reduced in frequency or delayed for 